\title{
Teen, Parent, and Clinician Expectations About Obesity and Related Conditions During the Annual Well-Child Visit
}

\author{
Andrew S. Bossick \\ Charles Barone \\ Gwen L. Alexander \\ Heather A. Olden \\ Tanya Troy \\ Andrea E. Cassidy-Bushrow
}

Follow this and additional works at: https://aah.org/jpcrr

Part of the Behavior and Behavior Mechanisms Commons, Dietetics and Clinical Nutrition Commons, Health Services Administration Commons, Pediatrics Commons, Preventive Medicine Commons, and the Public Health Education and Promotion Commons

\section{Recommended Citation}

Bossick AS, Barone C, Alexander GL, Olden HA, Troy T, Cassidy-Bushrow AE. Teen, parent, and clinician expectations about obesity and related conditions during the annual well-child visit. J Patient Cent Res Rev. 2017;4:114-24. doi: 10.17294/2330-0698.1444

Published quarterly by Midwest-based health system Advocate Aurora Health and indexed in PubMed Central, the Journal of Patient-Centered Research and Reviews (JPCRR) is an open access, peer-reviewed medical journal focused on disseminating scholarly works devoted to improving patient-centered care practices, health outcomes, and the patient experience. 


\title{
Teen, Parent, and Clinician Expectations About Obesity and Related Conditions During the Annual Well-Child Visit
}

\author{
Andrew S. Bossick, MPH, ${ }^{1}$ Charles Barone, MD,${ }^{2}$ Gwen L. Alexander, PhD, ${ }^{1}$ Heather A. Olden, MPH, \\ Tanya Troy, MPH, ${ }^{1}$ Andrea E. Cassidy-Bushrow, PhD ${ }^{1}$ \\ ${ }^{1}$ Department of Public Health Sciences, Patient-Engaged Research Center, Henry Ford Health System, Detroit, MI; \\ ${ }^{2}$ Department of Pediatric Administration, Henry Ford Health System, Detroit, MI
}

\begin{abstract}
Purpose This study aimed to examine family (patient, parent/guardian) and clinician preferences for identification and management of obesity and obesity-related conditions during the well-child visit.

Methods Four focus groups with teen patients $(n=16)$, four focus groups with parents $(n=15)$ and one focus group with providers $(n=12)$ were conducted using a structured moderator guide tailored to each population. Eligible patients had a well-child visit during the past 12 months and a diagnosis of overweight, obesity, hyperlipidemia or elevated blood pressure. Parents who attended their child's well-child visit and whose child met the diagnostic criteria were eligible. Teen focus groups were divided by gender (male/female) and age (14-15/16-17 years). Focus group transcripts were coded for concepts and themes using qualitative data and thematic analysis. Analysis was performed across groups to determine common themes and domains of intersect.
\end{abstract}

Results Teens and parents expect weight to be discussed at well-child visits and prefer discussions to come from a trusted clinician who uses serious, consistent language. Teens did not recognize the health implications from excess weight, and both parents and teens express the need for more information on strategies to change behavior. Providers recognize several challenges and barriers to discussing weight management in the well-child visit.

Conclusions A clinician-teen-family relationship built on trust, longevity, teamwork, support and encouragement can create a positive atmosphere and may improve understanding for weight-related messages for teens and families during a well-child visit. (J Patient Cent Res Rev. 2017;4:114-124.)

Keywords obesity, focus groups, pediatrics, well-child visit, patient-centered

$\mathrm{I}$ $\mathrm{n}$ the United States, approximately $17 \%$ of youth (2-19 years of age) were obese in 20112014. ${ }^{1}$ While screening for obesity is relatively straight-forward (ie, measuring height and weight), consistently relaying weight concerns to children and parents can be challenging. Obesity-related messages that children and their families receive during the wellchild visit have the potential to impact pediatric health outcomes; however, this impact may be positive or negative. Barriers to addressing pediatric obesity have

Correspondence: Andrea E. Cassidy-Bushrow, PhD, Henry Ford Health System, 1 Ford Place-5C, Detroit, MI, 48202, T: +1-313-874-6097, Email: acassid1@hfhs.org been shown to emerge at the practice, patient/family and community/society levels. ${ }^{2}$ Because family is a central component of a young person's life, barriers to addressing obesity at the family level may be of particular interest.

In previous studies, parents and providers have identified barriers to weight management as part of the well-child visit. In two studies of pediatric providers, barriers to weight-management identified were: parent and/or child not motivated to change diet or lifestyle; parents overweight and express less concern that child is overweight; practice-related barriers; limited clinician knowledge; low socioeconomic status and/or lack of insurance; limited community specialists and 
resources; and the sociocultural environment., ${ }^{2,3}$ Based on language used (ie, obese, overweight) by providers to convey weight-related messages, parents report mixed feelings on those messages; some are motivated to help their child reduce weight, some feel blame for their child's weight, and others plan to avoid future health care encounters. ${ }^{4,5}$ Clearly, appropriate messages relating to obesity from providers to pediatric patients and their families is essential.

A patient-centered outcome approach to health care incorporates health outcomes meaningful to each individual patient. The Institute of Medicine described a patient-centered approach as "providing care that is respectful and responsive to individual patient preferences, needs and values, and ensuring that patient values guide all clinical decisions." ${ }^{\prime \prime}$ In pediatrics, patient-centered approaches positively influence parent satisfaction. ${ }^{4}$ Prior qualitative studies using focus groups and interviews have examined pediatric screening, care and communication during the well-child visit from the parent ${ }^{7-11}$ or the provider perspective. ${ }^{12-14}$ To our knowledge, none of these included teens in the discussion to improve well-child visit outcomes.

Previous studies have shown success with family-based interventions for childhood obesity. ${ }^{15-18}$ Thus, a familycentered approach to obesity screening that includes teens, parents and providers in the conversation that shapes appropriate messaging of weight and weightrelated conditions during the well-child visit might improve pediatric outcomes. In this study, we aimed to examine pediatric patient, parent and clinician preferences for the identification and management of obesity and related conditions during the well-child visit.

\section{METHODS}

\section{Participants}

The Henry Ford Health System (HFHS) institutional review board approved the study protocol. HFHS is a comprehensive, integrated health care organization with locations across metropolitan Detroit, Michigan. In total, between December 2014 and June 2015, nine focus groups were held at HFHS and one additional focus group was held at an HFHS school-based clinic. Three distinct groups were recruited, using purposive sampling (parent, adolescent, provider groups). Recruitment flow for parents and teens is summarized in Figure 1. Given the time frame in which well-child clinical visits took place (2013-2014), International Classification of Diseases, Ninth Revision, Clinical Modification (ICD-9) codes were used to identify eligible participants instead of ICD-10 codes. ${ }^{19}$

Parent ( $n=15)$ Eligibility: Parents of children aged 2-18 years were recruited through advertisements $(n=7)$ and mailed letters $(n=8)$ to attend one of four focus groups. Only mothers responded, thus only mothers attended the focus groups. To identify eligible parents, we queried HFHS's electronic medical record (EMR). Parents of children with a well-child visit from December 2013 to December 2014 were identified. Eligibility criteria included: 1) their child attended a well-child visit within the previous 12 months; 2) they personally attended the well-child visit; and 3) their child was overweight, obese or morbidly obese (ICD9: 278.0-278.02) and/or had hypertension (796.2, 401.9) or hyperlipidemia $(272.0,272.4)$. The parent participant provided written informed consent.

Adolescent (n=16) Eligibility: Four focus groups were held with 9 boys and 7 girls aged 14 to 17 years. As described for parents, using the EMR, teens with a well-child visit from December 2013 to December 2014 were identified and considered eligible if they had a diagnosis of overweight, obese or morbid obesity and/or hypertension or hyperlipidemia. Groups were stratified by gender (male/female) and age (14-15/ 16-17 years). Teens provided written informed assent and a parent provided written informed consent.

Provider ( $n=12)$ Eligibility: Pediatric providers participated in a single focus group in June 2015. All providers delivered well-child visit care at HFHS. Providers were chosen at convenience from a monthly pediatric provider staff meeting. Attendance was not mandatory. All provider participants gave written informed consent.

Focus Group Enrollment: After eligibility was verified by EMR review and prior to being contacted by study staff, all participants randomly selected, excluding the provider group, were mailed an introduction letter. Those identified above were randomly selected to receive the introduction letter (randomization occurred after stratification by race, gender, age and condition(s) of interest to increase participation of a diverse group). 


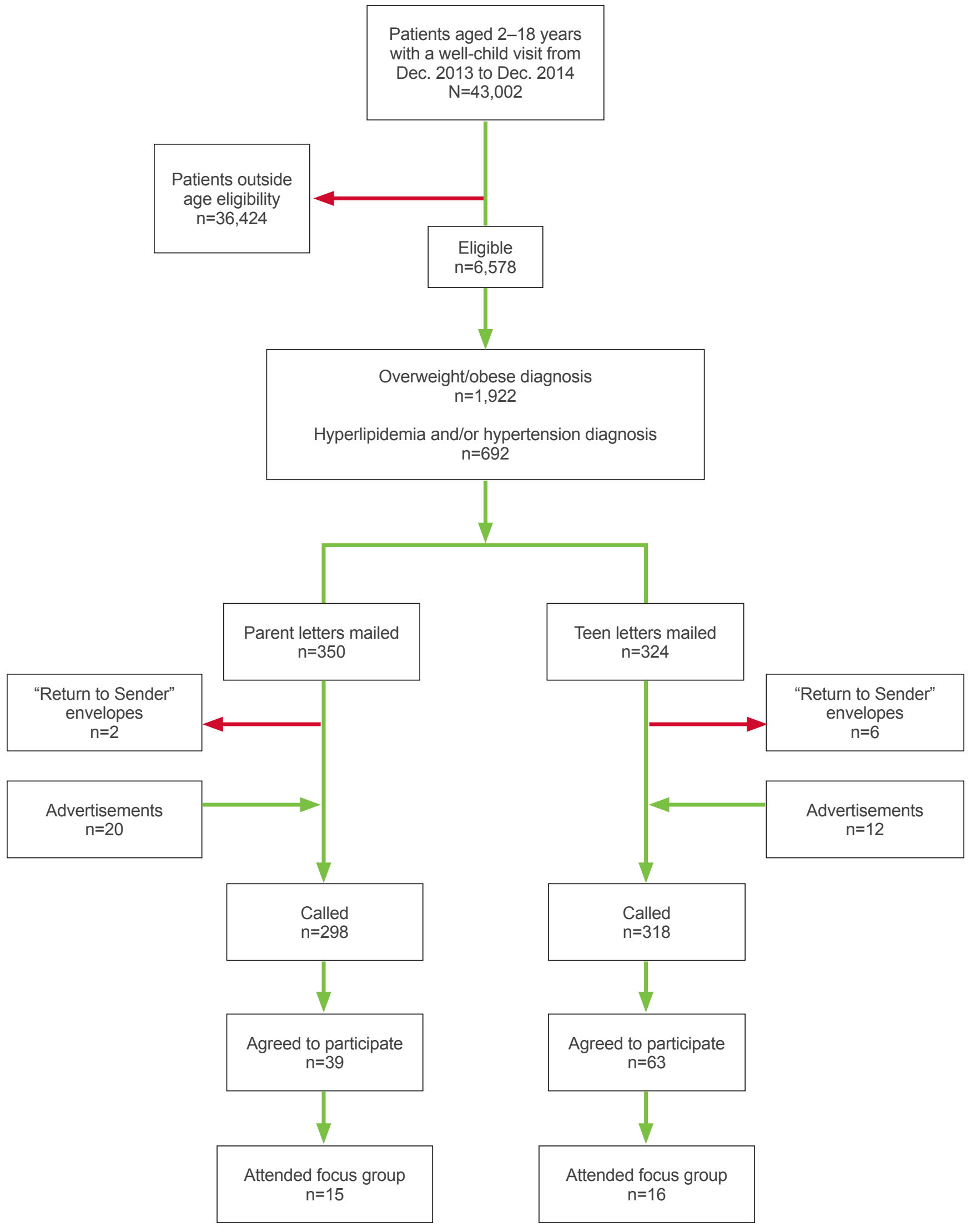

Figure 1. Parent and teen recruitment for focus groups. 
To increase enrollment, advertisements also were placed across HFHS sites inviting parents and teens to participate in focus groups. Those who responded were given their choice of dates to attend a focus group on a first-come-first-served basis. Recruitment to each focus group ended when 12 individuals agreed to participate.

Target focus group sample size was $\mathrm{N}=72(\mathrm{n}=8$ per group; $\mathrm{n}=43$ attended). Although attendance was low due to multiple factors, including weather, no additional recruitment occurred due to thematic saturation. Focus groups lasted $\sim 90$ minutes; participants were able to discontinue participation at any time.

\section{Data Collection}

Focus groups were audio-recorded and transcribed. Staff involvement for each group required one moderator, one assistant moderator and one notetaker (for detailed participant response information and to ease transcription errors). A moderator guide was created for each group (teen, parent, provider), with detailed questions for focus group cohesiveness. All participants, excluding clinicians, received $\$ 40.00$, and light refreshments were served. All groups were asked to complete a brief evaluation that included demographic information, focus group satisfaction and question comfort. The purpose of the focus groups was to identify parents', teens' and providers' views and experiences with wellchild visits and issues related to weight, blood pressure and cholesterol.

\section{Data Analysis}

Transcript content analysis occurred iteratively using the Framework Method for management and analysis of qualitative data. ${ }^{20}$ The initial organizational framework was taken from interview questions, which represented study goals. Preliminary descriptive codes to identify concepts expressed by participants were identified, discussed, revised and applied to the transcripts. After initial coding, transcripts were reviewed again to identify any additional subthemes and to check consistency of the coding. A list of unique topics in the response data were identified by the coauthors who comprised the analysis team. ${ }^{21}$

During the course of the analysis, one-third of both the parent and teen transcripts were randomly selected and read by all coders to identify and compare themes until no new themes were identified and consensus agreement on coding was achieved. Direct quotes to represent themes were identified by speaker number and date of the focus group session in the final analysis report. For both the teen and parent focus groups the intercoder agreement of topics and themes across the categories reached consensus, per established qualitative research standards. ${ }^{22,23}$

\section{RESULTS}

Descriptive characteristics are presented in Table 1. Teens ranged from being in 8 th to 11 th grade. Just over half of mothers were married $(n=8,53.3 \%)$. Mothers had a mean of $1.9 \pm 1.0$ children, and the mean age of their children was $15.2 \pm 6.1$ years.

Themes and concepts that emerged are presented hereafter for teens $(\mathrm{T})$, parents $(\mathrm{P})$ and providers $(\mathrm{C})$, and supported by italicized quotes. Table 2 presents a summary of major themes.

\section{Trust}

Parents and teens reported high trust in providers, with trust being consistent with greater expressions of comfort in care delivery and quality of care.

T: "If you don't trust your doctor, I mean, you shouldn't really go to them if you don't feel comfortable, say you don't trust, then you shouldn't go to that doctor."

Many teens and parents expressed the importance of their relationship with their doctor, which had been built over time, leading to trust and feeling comfortable

Table 1. Characteristics of Teen and Parent Focus Group Participants

\begin{tabular}{llll}
\hline & Race & $\mathbf{n}$ & $\begin{array}{c}\text { Age in years, } \\
\text { mean } \mathbf{\pm} \text { SD }\end{array}$ \\
\hline Teen $(\mathbf{n = 1 6 )}$ & & & \\
Boy & Black & 9 & $16.0 \pm 0.93$ \\
& White & 0 & \\
Girl & Black & 6 & $15.3 \pm 1.11$ \\
Parent $(\mathbf{n = 1 5 )}$ & White & 1 & \\
\multirow{2}{*}{ Mother } & & & \\
& Black & 9 & $46.9 \pm 6.13$ \\
& White & 4 & $47.0 \pm 5.48$ \\
& Other & 2 & $45.0 \pm 2.83$ \\
\hline
\end{tabular}

$S D$, standard deviation. 
Table 2. Focus Group Themes and Supporting Details

\begin{tabular}{|c|c|}
\hline Theme & Details \\
\hline Trust in provider & - Relationship built over time \\
\hline $\begin{array}{l}\text { Ecological perspective on sources of } \\
\text { information (parent, provider and teen team) }\end{array}$ & $\begin{array}{l}\text { - Provider-parent-child team } \\
\text { - Teens need parent support at home } \\
\text { - Teens also like friend support }\end{array}$ \\
\hline Provider language & $\begin{array}{l}\text { - Sensitive language } \\
\text { - Direct, serious approach }\end{array}$ \\
\hline First hearing about weight-related outcomes & $\begin{array}{l}\text { - Parents and teens doubt body mass index accuracy } \\
\text { - Teens expressed worry about weight }\end{array}$ \\
\hline $\begin{array}{l}\text { Awareness and/or knowledge of weight's } \\
\text { impact on health }\end{array}$ & $\begin{array}{l}\text { - Teens and parents do not recognize health impact } \\
\text { - Important to focus not just on physical, but also on mental and social health }\end{array}$ \\
\hline Goal setting & $\begin{array}{l}\text { - Teens and parents need more specific information } \\
\text { - Teens recognize providers have health in mind }\end{array}$ \\
\hline Appointment limitations and barriers & $\begin{array}{l}\text {-Almost universally, well-child visits are not long enough to discuss weight } \\
\text { - Need for in-office dietician }\end{array}$ \\
\hline
\end{tabular}

with the doctor. This allowed teens to feel they could ask questions and trust the answers.

P: "I have known him so long and he's always seemed to have their best interest at heart medically, so I do trust him. I don't take all of his advice, but I do trust him."

\section{Ecological Perspective of Information Sources (Parent, Provider and Teen Team)}

Most teens acknowledged their own responsibility for their health and described the support they received as "a team" made up of the provider, parent and themselves. Many providers also discussed a team approach, achieved by trying to engage the patient and family in the care conversation during the well-child visit.

$C$ : "We always try to engage the patient and, uh, obviously that means the family. So by engaging them ... more in the outcomes."

While the provider played an important role, most teens relied on their parents or grandparents as an interpreter during the visit and as support when at home.

T: "You can go to the doctor all day long. But when it comes to enforcing what the doctor says, the doctor doesn't live with you ... the role of the parent - and the grandparents."

T: "If it came from a parent, it would probably mean more because they have probably been through it, you know, like the high blood pressure.
And my mom has diabetes so she talks to me about it and it's like, you know, it clicks. Because most of the time doctors - they help you and they know it and they went to school for it, but then they haven't really experienced the type of stuff."

T: “Yeah, I - I like that my mom's there because it's like I don't have to pay attention to like all of the little nitpicky details, and my mom is like there writing everything down."

Although several teens described some support by parent and other family members, they also expressed lack of support, in particular, feelings of unhappiness for being singled out within the family. A few teens shared accounts of the family eating convenience food in front of them, similar to the notion of "sabotage" in weight management. ${ }^{24}$

T: "My mom going to pull up to Taco Bell. And she was like, 'We've got to get you a salad to eat.' And I'm like, 'You - but you about to eat a doggone taco in front of me. That's not right.",

Interestingly, many teens also wanted support from other teens experiencing unhealthy weight.

T: “... My best friend, like, she works out. She does basketball, but she was always tall and, you know, kind of big, too. So like by her doing the basketball and stuff, I noticed she lost weight, like a lot of it. So as I'm looking at her, I'm like, 'Okay, well, I 
know she's going to work out. 'So I'd be like, 'Well, let me go - I'll go work out, 'instead of just sitting at home saying, 'Oh, I should have worked out today, 'or 'I should have did this today., ",

T: "For me, it's like if it was my friends that were motivating me, they would have to be like trying to get their cholesterol down, too. Because if they're just like, 'Oh, you need to do this.' I'd be like, 'Okay, shut up!' Like, 'Get out of my face.' (Laughs) But if it's like somebody else who's going through it at the same time and we're both like actively trying at the same time ...."

\section{Provider Language}

All providers reported discussing health and lifestyle behaviors with families, but many tended not to emphasize weight during the conversation. They reflected on the body language of parents and children that signaled weight is a sensitive topic.

C: "Just how they feel about their weight in general. Most of the time I'll eyeball the patient and figure out whether or not they're overweight. So before I even show the graph with their dot way over ... I'll just say, 'How do you feel about your weight: too much, too little or just right? 'And then the conversation will be frank from that question." $C$ : "And we take cues from the patient or the parent ... You know, the parent starts, you know, withdrawing, and you know they are very upset about you talking and we have learned [over the years] how to do this."

Most providers perceived some parents as not recognizing issues with their child's weight. Nearly all providers stated that they preferred to discuss weight in terms of lifestyle modification, avoiding use of direct, weight-specific language such as "your BMI is too high." Many parents want the provider to acknowledge their teen's weight, explaining that teens do not respond well to parents but value it more coming from their provider. Most teens also stated the idea that they value and expect their provider to discuss weight.

T: "I think they have a right to say what they need to say to - to get you to do better... I mean the doctor needs to have a firm approach. I like doctors who are firm on approach but can be fun as well."

When providers discuss weight, almost all parents want a direct, serious approach that matches the severity of the problem. Those parents wanted the provider to bring their children into the weight discussion. Parents preferred the provider to be more direct, be proactive, offer action steps and discuss options with teens as opposed to simply talking about unhealthy weight.

P: "I would want her to be a part of the discussion ... because I think at, you know, at her age, she is mature enough to, you know, understand what she needs to do and what's happening."

P: "Well, my one daughter, um, is pretty sensitive about her size. And she has specifically asked, 'I don't want to see Doctor So-and-So. I'd like to see .... 'But it's - it's nothing that was, um, wrong or bad. It was really the truth, just not presented in how she wanted to hear it."

\section{First Hearing About Weight-Related Outcomes}

Several parents and teens doubted the accuracy and precision of body mass index (BMI) percentile charts. Height, weight and body type differences were reasons given to disagree with being labeled at an "unhealthy weight."

T: "Um, my doctor, he showed me a chart of basically where somebody my height, like, what their weight should be. And yeah, I didn't really think - well, okay, that's fine for some people, but I thought that was a little too much ... yeah. Like, I mean, though like, I thought that was too small to me.

P: “... I mean, they give you this chart, but I don't think that, uh, most children are within those guidelines. I mean, none of mine were ever within those guidelines because I had all big kids."

A few teens reported that the mention of their weightrelated health issues, without full explanation and strategy conversations, could be uncomfortable and cause worry.

T: "But because the doctor told me, it made me realize it is a medical problem and wasn't 'you should eat better' and stuff. It was like 'you need to, like, lose weight.' It was scary."

Similar to parent impressions, information and recommendations from a provider was accepted and taken seriously by nearly all teens. In terms of weight, some teens felt comfortable discussing weight if the clinician approached the conversation first. A majority of parents felt comfortable talking to the provider about weight. 
P: "I wish he was more proactive and would speak to her, you know, real: 'We've got - we need to do something about this. Let's do this. Let's try this,' versus, you know, mentioning it and just saying, 'Don't eat fast food or go to Weight Watchers.'”

\section{Awareness and/or Knowledge of Weight's Impact on Health}

Consequences of unhealthy weight were discussed. Some teens and parents did not appear to have a clear understanding of the potential negative sequelae of being overweight, while some parents and teens did recognize weight could cause medical and social consequences.

T: "I know what diabetes is, but I never understood why it's related to having a higher weight, but they never really explained it to me."

T: “... everything because they connect all together, so it's like diabetes connects to, you know, overweight, which lead - which is from, like, eating a lot of food and stuff."

Some parents reported knowing that having excess weight could result in diabetes and high blood pressure in teens. In addition, high cholesterol, liver problems, decreased lung function and knee pain were mentioned as possible health symptoms due to unhealthy weight by four parents. Most teens and parents also mentioned the social impact of weight, with concerns about finding clothes that fit, teasing, bullying and lack of social support as issues facing teens.

P: "Children are mean ... You know, they're made fun of occasionally ...."

P: "Just bullying and kids picking on them about their weight ...."

\section{Goal Setting}

Use of goal setting for weight management was mixed; several teens said that clinicians recommended goals that would help them achieve a healthier weight, although others reported wanting additional information. Goal setting and specific recommendations on effective exercise were requested by all teens.

T: "I would come to her about it, like, 'What are new diets I could do or new ways I could, you know, workout and start losing weight?' And she would let me know."
All providers mentioned many assumptions in the goalmaking process. Some did not consider that a pediatric patient would know or have a weight goal, saying the child's goal should come from the provider or parent, rather than asking the child his own weight goals.

$C$ : "They don't have a goal weight, no. These are kids. These are kids. They don't have goal weights."

Several parents reported not having specific weight goals for their children, and did not recall a specific weight goal provided by the pediatric physician. Most parents responded with general concerns of weight management, and their child being or feeling healthy.

P: "To be at a-a weight that they feel good at physically and emotionally."

Many teens also reflected on the provider's intentions, reporting providers as being supportive and interested in the teens' health, and saying that any resulting weight conversations were used as motivation to change health behaviors.

T: "They will probably know the most out of everybody else that'll tell you. They have the most background information ... plus, like, a parent helps, but the doctor knows like how to prevent you from going down the same road that your parents or grandparents or uncles went through. The parent helps, but yeah, the doctors do."

\section{Appointment Limitations and Barriers}

Some parents mentioned limitations of a long wait for an appointment and feeling that the provider was rushing during the well-child visit; however, all parents intended to remain with their same provider or practice due to the established provider-parent-teen relationship. Providers are aware that appointment length is insufficient to tackle weight-related issues.

P: "I just think that it would - more time. That's all ... yeah - that's the only complaint I have."

C: "Definitely. The fact that we're washing our hands at the sink and talking about it."

All parents desired additional information and guidance on lifestyle choices to help their children achieve a healthier weight. A few parents acknowledged the weight problem, feeling responsible that their child's weight management was not improving because they 
lacked tools to help the child become healthier. Most parents reported lack of confidence, especially if the parent also was overweight, expressing that they have predisposed their teens to an unhealthy weight. A few parents also wanted their doctors to give them referrals to a more effective weight-management program, recognizing their own limitations and the inadequacy of current support recommendations. All providers suggested advantages of having a dietician in the office to see the child immediately after the visit, rather than relying on the referral-based system.

$C$ : "A coach $-a-a$ nutritional coach in the office or somebody who, you know ...."

\section{DISCUSSION}

From our focus groups with clinicians, parents and teens, we identified some barriers, practices and beliefs about the well-child visit related to the screening and management of pediatric obesity and obesity-related conditions. To our knowledge, this is one of the few studies that conducted focus groups within these three groups, utilizing similar questions across the groups and finding similar thematic concepts across the informants. We found that although providers are hesitant to discuss obesity during the well-child visit, as long as the language used to do so is sensitive, both parents and teens expect, and even want, frank discussions with their provider about weight and weight-related issues.

Parents and teens reported trust in their clinicians, aligning trust with comfort in care delivery and quality, further illustrating the importance of the patient-family-clinician relationship. Providers acknowledged and engaged the patient and family in the care conversation. Our findings are consistent with a study of 282 pediatricians and 41 pediatric nurses, which showed that clinicians find importance in the doctor-patient-family relationship in developing trust, engaging the patient and family, effective interviewing and prioritizing the family's concerns. ${ }^{12}$

The extent to which teens acknowledge their responsibility for their weight management varied, with many relying on their parents and clinicians during the well-child visit for support and information gathering. Although teens described familial support, they also expressed inadequate support or sensitivity to dietary restrictions, substantiating that a child's dietary behavior change requires the commitment of the entire family. Examples from teens suggested that parents or other family members may act as enablers or saboteurs, for instance, eating unhealthy food right in front of them. A study of 99 young adults (aged 20-30 years) who were surveyed retrospectively about their motivation to diet as teens and their parent's behavior similarly found that parental support and involvement improved teens' overall dieting. ${ }^{25}$

We also learned that some teens seek support from other teens who are dealing with unhealthy weight. A study of 65 adolescent girls by Kulik et al also showed that friend support was more strongly associated with weight loss than family support. ${ }^{26}$

To our knowledge, only limited previous studies have addressed the pediatric patient's view on obesity. Martin et al, in a 2016 study of 5-12-year-old children with comorbid obesity and asthma, addressed emotional and behavioral consequences of obesity but not the role of health care, ${ }^{27}$ as we address herein. Of note, our participants - similar to those from a study conducted in Georgia ${ }^{28}$ — had limited understanding of the long-term health consequences of obesity, suggesting the need for both providers and potential school-based health courses to better convey the health risks associated with obesity.

While participating providers reported ease in identifying childhood obesity, they acknowledged difficulty with achieving improved weight status, with few pediatric patients reaching desired weight goals. They expressed that more discussion time during an appointment and additional support services (eg, clinic-based dietician) would be helpful. This is consistent with results from a study of 17 pediatricians from seven Wisconsin health systems that showed a lack of referral systems to effectively communicate weight-management support outside the clinic setting. ${ }^{29}$ Parents also desire longer visits with providers and other in-office support.

A barrier to effective weight counseling during a wellchild visit is lack of parental recognition of weight as a problem. ${ }^{30}$ Participating providers reported that not all parents recognize their child is overweight or realize the health impact of being overweight. As a result, 
many clinicians preferred to discuss weight in terms of lifestyle modification without explicitly referring to weight. In contrast, many parents wanted the provider to talk about weight, acknowledging the value and importance it would add for their children. We also learned that some parents mistrust the BMI charts that define body size; this issue of mistrust or doubt of the BMI chart has been reported previously. ${ }^{31}$

Teens echoed the sentiment that they expected, and wanted, the doctor to discuss weight and weight-related issues, acknowledging that the provider's motive was to improve their health. In some instances, a provider acknowledged a problem, without providing action steps or specific guidance, which leads to frustration from both parent and teen and may indirectly affect weight and the conversation about weight and weight management.

While we uncovered concerns and some fear from teens related to talking about health consequences of unhealthy weight, both parents and teens want a direct, serious approach when clinicians discuss weight, suggesting that clinicians should adopt a more decisive, serious tone. A patient-centered approach that gives the teen and parent time to ask questions, express feelings and talk about concerns and goals may strengthen the understanding of the problem and perhaps build commitment to make changes; teens view conversations with clinicians as motivating for behavior change.

Our focus group results suggest that teens who are dealing with overweight or overweight-related conditions wish to be and should be included and encouraged to participate, whenever possible, in the care conversation. Studies that have included teens in successful behavior change conversations often utilize a motivational interviewing approach, which includes asking for motivations, confidence level and values around the selected behavior change. ${ }^{32-34}$ Such an approach could be a natural fit for the pediatrician to employ to enhance a patient-centered approach during the well-child visit. Changing the weight conversation to one of active participation, goal setting and seriousness might help with prevention, improved behaviors and weight-reduction efforts for obesity and obesity-related conditions in pediatrics.
Screening for obesity, while noninvasive, may not be without risks. In 2005, Whitlock et al utilized an analytic framework that revealed no direct evidence that screening children for obesity places them at higher risk for labeling or psychological/behavioral consequences. ${ }^{35}$ At the family level, parental encouragement or criticism of a child's weight was associated with dysfunctional eating and dieting, and poorer physical self-perception and well-being. ${ }^{36}$ However, parental receipt of weight information about their child did not yield negative effects on self-esteem or teasing. ${ }^{37}$ In our study, while parents expressed concerns that the emotional impact of obesity be discussed by their child's provider, there was no mention of negative experiences with obesity screening; rather, this was considered expected. At least one mother did mention that she changed her child's provider based on the language used to diagnose obesity, and this does suggest that it is of importance to craft clear messages without sounding accusatory or blaming.

\section{Strengths and Limitations}

There are several limitations in our exploratory investigation. First, our sample is from one geographic urban area and was not balanced racially/ethnically. Second, our sample size is small in all groups, limiting representativeness. Despite this, we identified recurring themes across our focus groups and across our three respondent groups. Third, in our provider focus groups, two clinicians dominated the conversation. However, findings from our provider group echoed previously published research.

A strength of this project is the inclusion of clinicians, parents and teens in the evaluation of well-child visits to enhance a patient-centered approach. Including the voices of teens on the same questions asked to clinicians and parents offers valuable and novel information. Nearly all of our teen participants were black, a group at disproportionately higher risk of obesity than their white counterparts ${ }^{38}$ yet also underrepresented in research studies. In one focus-group study of obesityrelated health specifically conducted in AfricanAmerican teens, health care issues were not addressed; however, similar to our findings, families and peers were viewed as important in handling weightmanagement issues. ${ }^{39}$ 


\section{CONCLUSIONS}

A provider-adolescent-parent relationship built on trust, teamwork, support and encouragement creates a positive atmosphere and could improve understanding of weight-related messages during a well-child visit. Teens and parents described appreciation and benefits of long-standing patient-provider relationships, which improve comfort and potential for positive discussions of weight. Parents expressed feeling inadequately prepared to manage their teen's weight.

More research is needed to address teen and parent needs to manage weight, along with mechanisms to support valued provider information sharing. Future studies are planned that will incorporate our findings into a web-based, clinician-oriented, motivational interviewing-style educational module that reinforces time-efficient and effective patient-centered care.

\section{Patient-Friendly Recap}

- Obesity is common among American children, with $17 \%$ meeting the medical definition as of 2014.

- The authors studied how weight concerns were addressed at routine annual clinic visits, and how those conversations were perceived by teenagers, parents and health providers.

- They found that teens (ages 14-17) prefer physicians take a direct, serious approach to the subject of weight management as well as advise actionable steps for improvement.

- Teens view conversations with clinicians as motivating for behavior change. A patientcentered approach that allows time to ask questions, express feelings and discuss goals may help weight-reduction efforts in pediatrics.

\section{Acknowledgments}

The authors acknowledge and thank the project patient advisors, Danelle Marsh and Christina Byrd, for reviewing this manuscript.

\section{Conflicts of Interest}

None.

\section{Funding Sources}

The Agency for Healthcare Research and Quality funded this study (R24HS022417). Study sponsors did not play a role in the collection, analysis and interpretation of the data nor in the writing of this manuscript. The Henry Ford Health System PatientEngaged Research Center provided focus group moderation and data analysis.

\section{References}

1. Ogden CL, Carroll MD, Lawman HG, et al. Trends in obesity prevalence among children and adolescents in the United States, 1988-1994 through 2013-2014. JAMA. 2016;315:2292-9. CrossRef

2. Spivack JG, Swietlik M, Alessandrini E, Faith MS. Primary care providers' knowledge, practices, and perceived barriers to the treatment and prevention of childhood obesity. Obesity (Silver Spring). 2010;18:1341-7. CrossRef

3. Findholt NE, Davis MM, Michael YL. Perceived barriers, resources, and training needs of rural primary care providers relevant to the management of childhood obesity. $J$ Rural Health. 2013;29 Suppl 1:s17-24. CrossRef

4. October TW, Hinds PS, Wang J, Dizon ZB, Cheng YI, Roter DL. Parent satisfaction with communication is associated with physician's patient-centered communication patterns during family conferences. Pediatr Crit Care Med. 2016;17:490-7. CrossRef

5. Puhl RM, Peterson JL, Luedicke J. Parental perceptions of weight terminology that providers use with youth. Pediatrics. 2011;128:e786-93. CrossRef

6. Institute of Medicine (US) Committee on Quality of Health Care in America. Crossing the quality chasm: a new health system for the 21st century. Washington, DC: National Academies Press, 2001.

7. Radecki L, Olson LM, Frintner MP, Tanner JL, Stein MT. What do families want from well-child care? Including parents in the rethinking discussion. Pediatrics. 2009;124:858-65. CrossRef

8. Sharifi M, Marshall G, Goldman R, et al. Exploring innovative approaches and patient-centered outcomes from positive outliers in childhood obesity. Acad Pediatr. 2014;14:646-55. CrossRef

9. Schempf AH, Minkovitz CS, Strobino DM, Guyer B. Parental satisfaction with early pediatric care and immunization of young children: the mediating role of age appropriate well-child care utilization. Arch Pediatr Adolesc Med. 2007;161:50-6. CrossRef

10. Young KT, Davis K, Schoen C, Parker S. Listening to parents. A national survey of parents with young children. Arch Pediatr Adolesc Med. 1998;152:255-62.

11. Schuster MA, Duan N, Regalado M, Klein DJ. Anticipatory guidance: what information do parents receive? What information do they want? Arch Pediatr Adolesc Med. 2000;154:1191-8. CrossRef

12. Tanner JL, Stein MT, Olson LM, Frintner MP, Radecki L. Reflections on well-child care practice: a national study of pediatric clinicians. Pediatrics. 2009;124:849-57. CrossRef

13. Fenikilé TS, Ellerbeck K, Filippi MK, Daley CM. Barriers to autism screening in family medicine practice: a qualitative study. Prim Health Care Res Dev. 2015;16:356-66. $\underline{\text { CrossRef }}$ 
14. Polaschek L, Polaschek N. Solution-focused conversations: a new therapeutic strategy in well child health nursing telephone consultations. J Adv Nurs. 2007;59:111-9. CrossRef

15. Epstein LH, Paluch RA, Roemmich JN, Beecher MD. Familybased obesity treatment, then and now: twenty-five years of pediatric obesity treatment. Health Psychol. 2007;26:381-91. CrossRef

16. Magarey AM, Perry RA, Baur LA, et al. A parent-led familyfocused treatment program for overweight children aged 5 to 9 years: the PEACH RCT. Pediatrics. 2011;127:214-22. CrossRef

17. Nowicka P, Flodmark CE. Family in pediatric obesity management: a literature review. Int J Pediatr Obes. 2008;3 Suppl 1:44-50. CrossRef

18. Kalarchian MA, Levine MD, Arslanian SA, et al. Familybased treatment of severe pediatric obesity: randomized, controlled trial. Pediatrics. 2009;124:1060-8. CrossRef

19. Centers for Disease Control and Prevention. International Classification of Diseases, Tenth Revision, Clinical Modification (ICD-10-CM). www.cdc.gov/nchs/icd/ icd10cm.htm. August 22, 2016. Accessed December 6, 2016.

20. Gale NK, Heath G, Cameron E, Rashid S, Redwood S. Using the framework method for the analysis of qualitative data in multi-disciplinary health research. BMC Med Res Methodol. 2013;13:117. CrossRef

21. Ryan GW, Bernard HR. Techniques to identify themes. Field Methods. 2003;15:85-109. CrossRef

22. Golafshani N. Understanding reliability and validity in qualitative research. The Qualitative Report. 2003;8:597-606.

23. Thomson SB. Qualitative research: validity. Journal of Administration \& Governance. 2011;6:77-82.

24. Romo LK. An examination of how people who have lost weight communicatively negotiate interpersonal challenges to weight management. Health Commun. 2017 Feb 2 [Epub ahead of print]. CrossRef

25. Katz I, Madjar N, Harari A. Parental support and adolescent motivation for dieting: the Self Determination Theory perspective. J Psychol. 2015;149:461-79. CrossRef

26. Kulik N, Valle CG, Tate DF. Friend and family support for weight loss in adolescent females. Child Obes. 2016;12:44-51. $\underline{\text { CrossRef }}$

27. Martin MA, Floyd EC, Nixon SK, Villalpando S, Shalowitz M, Lynch E. Asthma in children with comorbid obesity: intervention development in a high-risk urban community. Health Promot Pract. 2016;17:880-90. CrossRef
28. Sylvetsky AC, Hennink M, Comeau D, et al. Youth understanding of healthy eating and obesity: a focus group study. J Obes. 2013;2013:670295. CrossRef

29. Traun BD, Flood TL, Meinen A, Daniels M, Remington PL. A qualitative pilot study of pediatricians' approach to childhood obesity. WMJ. 2016;115:134-8.

30. Mareno N. Parental perception of child weight: a concept analysis. J Adv Nurs. 2014;70:34-45. CrossRef

31. Gillison F, Beck F, Lewitt J. Exploring the basis for parents' negative reactions to being informed that their child is overweight. Public Health Nutr. 2014;17:987-97. CrossRef

32. Carcone AI, Jacques-Tiura AJ, Brogan Hartlieb KE, Albrecht T, Martin T. Effective patient-provider communication in pediatric obesity. Pediatr Clin North Am. 2016;63:525-38. CrossRef

33. Broccoli S, Davoli AM, Bonvicini L, et al. Motivational interviewing to treat overweight children: 24-month follow-up of a randomized controlled trial. Pediatrics. 2016;137:e20151979. CrossRef

34. Borrello M, Pietrabissa G, Ceccarini M, Manzoni GM, Castelnuovo G. Motivational interviewing in childhood obesity treatment. Front Psychol. 2015;6:1732. CrossRef

35. Whitlock EP, Williams SB, Gold R, Smith PR, Shipman SA. Screening and interventions for childhood overweight: a summary of evidence for the US Preventive Services Task Force. Pediatrics. 2005;116:e125-144. CrossRef

36. Gillison FB, Lorenc AB, Sleddens EF, Williams SL, Atkinson L. Can it be harmful for parents to talk to their child about their weight? A meta-analysis. Prev Med. 2016;93:135-46. CrossRef

37. Falconer CL, Park MH, Croker H, et al. The benefits and harms of providing parents with weight feedback as part of the national child measurement programme: a prospective cohort study. BMC Public Health. 2014;14:549. CrossRef

38. Centers for Disease Control and Prevention. CDC Health Disparities and Inequalities Report — United States, 2013. MMWR Morb Mortal Wkly Rep. 2013;62(Suppl 3):1-187.

39. St George SM, Wilson DK. A qualitative study for understanding family and peer influences on obesityrelated health behaviors in low-income African-American adolescents. Child Obes. 2012;8:466-76. CrossRef

(C) 2017 Aurora Health Care, Inc. 